\title{
Pharmacology and Metabolism of Anidulafungin, Caspofungin and Micafungin in the Treatment of Invasive Candidosis - REVIEW OF THE LITERATURE
}

\author{
G. Kofla, M. Ruhnke \\ Charité University Medicine, Department of Medicine, Division of Oncology/Hematology, Charité Campus Mitte, Berlin, Germany
}

\begin{abstract}
Echinocandins represent the newest class of antifungal agents. Currently, three echinocandins, anidulafungin, caspofungin and micafungin are licensed for clinical use in various indications. They act as inhibitors of $\beta$-(1,3)-glucan synthesis in the fungal cell wall and have a favorable pharmacological profile. They have a broad spectrum of activity against all Candida species. Higher MIC's have been observed against C. parapsilosis and C. guilliermondii. Data from clinical trials for invasive Candida infections / candidaemia suggest that the clinical outcome of patients treated with either drug may be very similar. A comparison has been done between caspofungin and micafungin but for anidulafungin a comparative trial with another echinocandin is still lacking. All three drugs are highly effective if not superior to treatment with either fluconazole or Amphotericin B, particularly in well-defined clinical settings such as invasive Candida infections, Candida oesophagitis and candidaemia. Differences between the three echinocandins with regard to the route of metabolism, requirement for a loading dose, dose adjustment in patients with moderate to severe hepatic disease and different dosing schedules for different types of Candida infections have to be considered. Relevant drug-drug interactions of Caspofungin and Micafungin are minimal. Anidulafungin has no significant drug interactions at all. However, echinocandins are available only for intravenous use. All three agents have an excellent safety profile.
\end{abstract}

Key words: echinocandins, anidulafungin, caspofungin, micafungin, pharmacology, antifungal agents

\section{INTRODUCTION}

Despite the rapid development of the triazoles in the 1990s and the availability of liposomal amphotericin which replaced conventional amphotericin B and provided alternative options for treating invasive fungal infections, complications due to fungal infections remain a serious clinical problem, especially in immunocompromised patients. This population includes transplant recipients (solid organ and stem cells), patients with cancer, patients treated in internal and surgical ICU's or other treated for diseases with immunosuppressive agents and patients with
HIV/AIDS. Many factors have contributed to the rise of several fungal infections in the last decades, including novel and more aggressive immunosuppressive drugs and regimens, a high frequency of instrumentation and catheterization, frequent application of intravenous catheters, long-term parenteral nutrition and prolonged use of broad-spectrum antibiotics. Enhanced survival in intensive care units due to advances in medicine also increases the patient population susceptible to secondary fungal infections $[1 ; 2]$.

Candida infections have contributed significantly to the mortality in immunosuppressed patients and treatment outcomes for invasive candidosis are still less than optimal. Candidaemia has been observed to be the fourth leading cause of bloodstream infections in pediatric patients, cancer patients, and hospitalized patients with mortality rates from $20 \%$ in pediatric patients to $47 \%$ in intensive care unit patients [3-5]. Candida albicans is still the most commonly found isolate. However, there has been a shift towards more azoleresistant species (e.g. Candida glabrata) found in some institutions, paralleled by a reduced susceptibility to azole antifungals such as fluconazole which is commonly used for superficial and invasive Candida infections [6; 7]. The expert Panel of the IDSA favours an echinocandin for first-line treatment of candidaemia in non-granulocytopenic patients with moderately severe to severe illness, as first-line treatment for granulocytopenic patients, patients recently exposed to azole, candidaemia caused by C. glabrata, and / or suspected invasive candidosis caused by C. glabrata or C. krusei [8].

Echinocandins are cyclic lipopeptide molecules that inhibit the synthetic cell-wall enzyme complex $\beta-1,3-$ $D$-glucan synthase. Inability of the organism to build $\beta-1,3-D$-glucan destabilizes the integrity of the fungal cell wall, leading to osmotic instability and cell death $[9 ; 10]$. Echinocandins are fungicidal against yeast and fungistatic against molds and have a similar spectrum of antifungal activity. In addition, echinocandin activity can persist in a drug free environment following drug exposure (post-antifungal effect) [11].

There are three echinocandins approved by the European Medicines Agency (EMEA) for the use in Europe, 1) Caspofungin (MK-0991, Cancidas ${ }^{\circledR}$; Merck \& Co., Inc., Whitehouse Station, NJ, USA) derived from 
Glarea lozoyensi, was approved first in 2001; 2) Anidulafungin (VER-002, LY303366, Eraxis ${ }^{\circledR}$, Pfizer, Inc., New York, NY, USA) derived from Aspergillus nidulans and approved in 2007; and 3) Micafungin (FK463, Mycamine ${ }^{\circledR}$, Astellas Pharma US, Inc., Deerfield, IL, USA) derived from Coleophoma empedri was approved in 2008 [12-14]. Licensed indications in Europe differ between the three agents. Anidulafungin is indicated to treat invasive candidosis in adults who are not granulocytopenic but not in children or adolescents below the age of 18 years. Caspofungin is indicated to treat adults, adolescents and children with invasive candidosis, invasive aspergillosis when the patient does not respond to or does not tolerate amphotericin B or itraconazole; suspected fungal infections (such as due to Candida or Aspergillus) when the patient is febrile and granulocytopenic. Micafungin is indicated for adults, adolescents and children (including neonates) in the treatment of invasive candidosis, and prophylaxis of Candida infection in patients undergoing allogeneic haematopoietic stem cell transplantation or patients who are expected to have granulocytopenia (absolute neutrophil count $<500$ cells / $\mu \mathrm{l})$ for 10 or more days. In addition, micafungin is licensed for treatment of oesophageal candidosis in adults for whom intravenous therapy is appropriate [12-14].

As the incidence of fungal infections caused by fluconazole-resistant non-Candida-albicans species is increasing, echinocandins have become an important group in the treatment of these types of infections because of lack of cross-resistance to azoles [15]. Their limited toxicity and a favorable drug-drug interactions profile make them a viable alternative to conventional treatment.

\section{CHEMISTRY}

The echinocandins have significant structural differences (s. Fig. 1). Echinocandins are large lipopeptide molecules synthetically modified from the fermentations broths of various fungi. They are amphiphilic cyclic hexapeptides with $\mathrm{N}$-linked acyl lipid side-chain and a molecular weight of about 1200 . The molecular formula of caspofungin-acetate is $\mathrm{C}_{52} \mathrm{H}_{88} \mathrm{~N}_{10} \mathrm{O}_{15} \cdot 2 \mathrm{C}_{2} \mathrm{H}_{4} \mathrm{O}_{2}$ and it has a fatty acid side chain. Micafungin sodium has a complex aromatic side-chain (3,5-diphenyl-sub- stituted isoxazole) and its molecular formula is $\mathrm{C}_{56} \mathrm{H}_{70} \mathrm{~N}_{9} \mathrm{NaO}_{23} \mathrm{~S}$. Anidulafungin's molecular formula is $\mathrm{C}_{58} \mathrm{H}_{73} \mathrm{~N}_{7} \mathrm{O}_{17}$ and it has an alkoxytriphenyl side chain. The side chains intercalate with the phospholipid bilayer of the cell membrane $[1 ; 16]$.

Anidulafungin and Micafungin are freely soluble in water. Caspofungin is freely soluble in water and methanol, and slightly soluble in ethanol. Because of their inconsistent oral absorption, echinocandins are available only for intravenous use. Micafungin is prepared as a powder ready for reconstitution and excipients include lactose, citric acid, and sodium hydroxide. Reconstituted solution is stable at room temperatures for $48 \mathrm{~h}$ (if protected from light). Caspofungin is provided as a lyophylised powder and excipients include sucrose, mannitol, acetic acid, and sodium hydroxide. It can be stored (refrigerated) for up to $24 \mathrm{~h}$ after reconstitution. Anidulafungin is also provided as a lyophylised powder for reconstitution. The vial must be reconstituted with water for injections and subsequently diluted with $(0.9 \%)$ sodium chloride for infusion or $(5 \%)$ glucose for infusion. Chemical and physical in-use stability of the infusion solution has been demonstrated for 24 hours at $5^{\circ} \mathrm{C}$ [12-14; 16].

\section{MECHANISM OF ACTION}

The target of echinocandins, $\beta$-1,3-D-glucan synthase is an integral part of the fungal cell wall and consists of two subunits, Fksp and Rho1p. Fksp is the active side of the enzyme and is encoded by three genes (FKS1, FKS2 and FKS3). FKS1 transcription is cell-cycle regulated, and linked to cell-wall remodeling. FKS2 transcription is calcineurin-dependent [2]. Calcineurin-inhibitors such as tacrolimus seem to enhance the echinocandin activity in vitro, similar as it is supposed for synergistic activity of fluconazole with cyclosporine A [17; 18]. Rho1p is thought to be a key switch, driving or arresting the synthesis of $\beta-1,3$-glucan. $\beta-1,3-D$-glucan provides along with chitin the integrity and shape of the cell wall. Blocking of its synthesis results in osmotic lysis of the cell, thus leading to fungicidal activity of the echinocandins against Candida species [16]. The cell-wall is not a part of mammalian cells, and therefore an excellent target for antifungal agents.

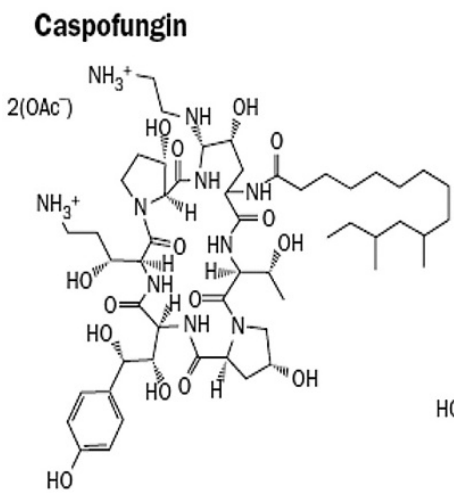

Micafungin

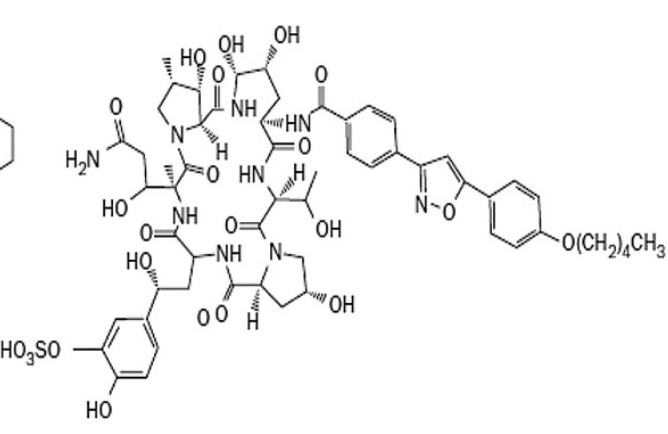

Anidulafungin

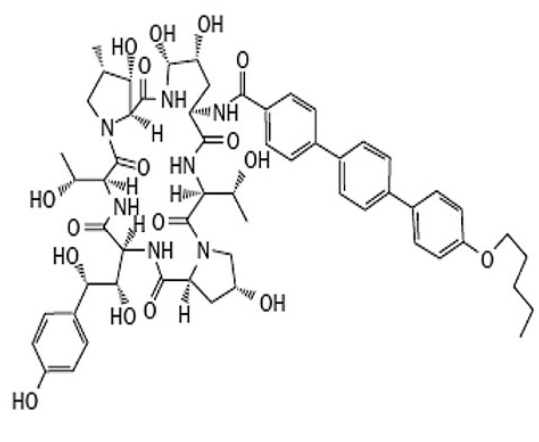

Fig. 1. Chemical structure of echinocandins. 


\section{SPECTRUM OF ACTIVITY}

Echinocandins are know to be active against Candida and Aspergillus species but are also active against Pneumocystis jirovecii. They are not active at clinically relevant concentrations against Zygomycetes, Cryptococcus neoformans, or Fusarium species [2]. Considering the family of yeast which is the main subject of this review, echinocandins display in vitro and in vivo fungicidal activity against most Candida species, including Candida albicans, Candida glabrata, Candida tropicalis, Candida dubliniensis, and Candida krusei. They are less active against Candida parapsilosis and Candida guilliermondii, with higher minimum inhibitory concentrations for these species [19]. The MIC50 of caspofungin and anidulafungin against $C$. albicans ranges from $<0.01 \mu \mathrm{g} / \mathrm{mL}$ to $>8 \mu \mathrm{g} / \mathrm{mL}$, and that of micafungin from $\leq 0.01 \mu \mathrm{g} / \mathrm{mL}$ to $0.5 \mu \mathrm{g} / \mathrm{mL}$. The MIC90 against $C$. albicans ranges from $0.01 \mu \mathrm{g} / \mathrm{mL}$ to $0.5 \mu \mathrm{g} / \mathrm{mL}$ for anidulafungin; $0.01 \mu \mathrm{g} / \mathrm{mL}$ to 0.25 $\mu \mathrm{g} / \mathrm{mL}$ for micafungin, and from $0.12 \mu \mathrm{g} / \mathrm{mL}$ to 1 $\mu \mathrm{g} / \mathrm{mL}$ for caspofungin, respectively [19-22]. Accordingly, the CLSI subcommittee has decided to recommend a "susceptible only" breakpoint MIC of $<$ or $=$ $2 \mu \mathrm{g} / \mathrm{ml}$ due to the lack of echinocandin resistance in the population of Candida isolates [20].

The activity is comparable between the three agents and all of them present much lower MICs than amphotericin B and fluconazole against common Candida spp. [19]. The exception are Candida parapsilosis and Candida guilliermondii for which minimal inhibitory concentrations are typically higher and range from $0.5 \mu \mathrm{g} / \mathrm{mL}$ to $4.0 \mu \mathrm{g} / \mathrm{mL}$. Breakthrough bloodstream infections (BSI) with Candida parapsilosis and Candida guilliermondii as well as progressive Candida oesophagitis with Candida albicans have been observed in patients receiving caspofungin [23-28]. Some data indicate that anidulafungin could have lower MICs against C. parapsilosis and C. glabrata strains that demonstrate enhanced MICs to caspofungin and micafungin [23]. Whether this is clinically meaningful needs to be established.

\section{RESISTANCE}

The incidence of resistance to echinocandins is rare, but some case reports have illustrated the potential for resistance development [24-27;29]. Mutations of the FKS gene have been indentified to cover echinocandins resistance in most cases. Specifically FKS1 mutations were found to be associated with a profound decrease in susceptibility to echinocandins $[16 ; 24 ; 30 ; 31]$. It is supposed that these mutations result in cross-resistance to all agents in the class. The second distinct mechanism potentially conferring resistance to echinocandins is the presence of a drug efflux pumps in the fungal cell wall. The cdr2p gene (also known to contribute to fluconazole resistance in $C$. albicans) was associated with an increase in MICs of caspofungin. The same phenomenon, but to a lesser extent, was seen for cdr1p [32].

\section{PHARMACODYNAMICS}

All three echinocandins exhibit concentration-dependent killing against most Candida spp. over a broad concentration range. The killing efficacy is correlated with plasma peak $\left(\mathrm{C}_{\max }\right) / \mathrm{MIC}$ ratio or area under the concentration-time curve (AUC)/MIC ratio $[11 ; 33$; 34]. Interestingly, echinocandin activity can be still observed in a drug free environment following drug exposure. It is known as the post - antifungal effect and is also concentration dependent, with higher concentrations resulting in longer post-antifungal effects [35; 36]. According to that phenomenon, extended dosing intervals might be an option as shown in an animal model of mice treated with micafungin for disseminated candidosis [37-39]. In children, a pharmacokinetic study found that alternate-day dosing of micafungin given as antifungal prophylaxis plasma levels were found to remain above the MIC's of susceptible fungal pathogens [40]. However, further studies are needed to support this procedure in clinical practice. Another interesting phenomenom is the "eagle effect". In vitro, a paradoxical increase in fungal growth ("paradoxical growth", "eagle effect") could be observed if echinocandin concentration was increased above the organism's MIC [41-43]. However, this effect varies remarkably between the three echinocandins [44]. In four different Candida species alterations were observed in cell wall components and ultrastructure associated with paradoxical growth [42]. In paradoxical growth cells, $\beta$-1,3-glucan content decreased from 2.7to 7.8-fold, whereas chitin content increased from 4.0to 6.6-fold. High concentrations of the echinocandin could depress resistance mechanisms but the clinical relevance of this phenomenon is unknown.

\section{ACTIVITY AGAINST BIOFILMS}

Candidemia is often associated with intravascular catheters, which can be complicated by building of biofilms that consist of sessile cells. Contrary to fluconazole, all three echinocandins were shown to be active against biofilms. Caspofungin, micafungin and anidulafungin exhibit activity against sessile cells of $C$. albicans, C. dubliniensis, C. glabrata and C. krusei which can be of clinical relevance [45-49].

\section{Pharmacokinetics}

In general, because of their large molecular weight, echinocandins are poorly bioavailable for oral use, and therefore they are approved only for intravenous administration. However, one echinocandin (enfumafungin) potentially suitable for oral use is currently under investigation [50]. All echinocandins distribute well into tissues, but none of them penetrate sufficiently the CNS or the eye, therefore they are not recommended as drug of choice for treatment of patients with fungal meningitis or endophthalmitis [8; 51]. Animal models suggest the potential usefulness of the echinocandins in Candida meningoencephalitis although higher doses might be required (as studied for micafungin) but this needs further clinical investigation $[34 ; 52]$. The echinocandins are not dialyzable, and there is no need for supplemental doses after haemodialysis. Dose adjustment is also not required in patients with renal impairment. Pharmacokinetic data in the public domain to support this 
Table 1. Pharmacokinetics of echinocandins for the treatment of Candida infections

\begin{tabular}{lccc}
\hline Parameter & anidulafungin & caspofungin & micafungin \\
\hline Mode of administration & $\mathrm{IV}$ & $\mathrm{IV}$ & $\mathrm{IV}$ \\
Dose linearity & + & + & + \\
Oral availability [\%] & $\mathrm{n} / \mathrm{a}$ & $\mathrm{n} / \mathrm{a}$ & $\mathrm{n} / \mathrm{a}$ \\
Plasma protein binding [\%] & 99 & 97 & 99 \\
Volume of distribution [L] & $30-50$ & $\mathrm{n} / \mathrm{a}$ & 18 \\
Elimination half-life [h] & 24 & $9-11$ & $10-17$ \\
Route of elimination & $\mathrm{D}$, & $\mathrm{D} / \mathrm{M}$ & $\mathrm{M}$ \\
& $\mathrm{F}$ & $\mathrm{U}>\mathrm{F}$ & $\mathrm{F}>\mathrm{U}$ \\
\hline
\end{tabular}

$\mathrm{E}=$ excretion unchanged; $\mathrm{M}=\mathrm{drug}$ is metabolised; $\mathrm{D}=\mathrm{drug}$ is degraded; $\mathrm{U}=$ urine; $\mathrm{F}=$ faeces

statement are currently only available for anidulafungin [53].

A high protein binding is typical for all three echinocandins (>95\%; see Table 1$)$. None of them is a major p-glycoprotein substrate and none is significantly metabolized by the cytochrome P450 [16]. Of note, when caspofungin is co-administered with inducers of metabolic enzymes, an increase in the daily dose to 70 $\mathrm{mg}$, following the $70 \mathrm{mg}$ loading dose, should be considered in adult patients. Major differences are related to the route of metabolism and half- life [54-57]. Therapeutic drug monitoring is not generally indicated. However, plasma levels of caspofungin may be increased in severely ill patients treated in the surgical ICU, in particular when albumin concentration in plas$\mathrm{ma}$ is low [58; 59]. For micafungin, a study on population pharmacokinetics found that patients weighing $66.3 \mathrm{~kg}$ or more need a higher daily dose of micafungin $(150 \mathrm{mg})$ to achieve an AUC0-24 comparable to patients $<66.3 \mathrm{~kg}$ receiving $100 \mathrm{mg} /$ day [57].

Caspofungin is characterized by a moderate nonlinear pharmacokinetics with increased accumulation as the dose is increased, and a dose dependency in the time to reach steady state upon multiple-dose administration. In contrast to a short $\alpha$-phase and a predominat $\beta$-phase that exhibits $\log$ linearity, a long $\gamma$-phase appears to be nonlinear and responsible for the accumulation of caspofungin over time. The dosage of caspofungin is a $70-\mathrm{mg}$ loading dose followed by 50 $\mathrm{mg}$ once/day, resulting in a through concentration of at least $1 \mu \mathrm{g} / \mathrm{mL}$. Higher dosages of caspofungin (up to $150 \mathrm{mg} / \mathrm{d}$ ) have been studied in clinical trials suggesting a higher efficacy in subgroups of patients and a dose-related response [60; 61]. The metabolism is slow, it undergoes spontaneous disintegration to an open-ring compound followed by peptide hydrolysis and $\mathrm{N}$-acytylation into two inactive metabolites in the liver $[62 ; 63]$. The half-life of caspofungin is 9-11h (s. Table 1). An additional gamma-phase also occurs with a half-life of 45 hours. The elimination of caspofungin from plasma is slow with a clearance of 10-12 $\mathrm{ml} /$ minute. Approximately $75 \%$ of a radioactive dose was recovered during 27 days: $41 \%$ in urine and $34 \%$ in faeces. A small amount of caspofungin is excreted unchanged in urine (approximately $1.4 \%$ of dose) [13].

Micafungin is characterized by linear pharmacokinetics over the daily dose range of $12.5 \mathrm{mg}$ to $200 \mathrm{mg}$ and $3 \mathrm{mg} / \mathrm{kg}$ to $8 \mathrm{mg} / \mathrm{kg}$. There is no evidence of systemic accumulation with repeated administration and steady-state is reached within 4 to 5 days. It is metabolized into three metabolites. The first metabolite is formed by arylsulfatase and further degraded by catechol-O-methyl-transferase to the second metabolite. The third metabolite is the result of the side chain hydrolysis by CYP3A, but this pathway does not play a significant role in the drug metabolism. The degradation products are excreted slowly over many days, mainly in the bile. Following intravenous administration concentrations of micafungin show a biexponential decline. The drug is rapidly distributed into tissues. In systemic circulation, micafungin is highly bound to plasma protein $(>99 \%)$, primarily to albumin. Binding to albumin is independent of micafungin concentration $(10-100 \mu \mathrm{g} / \mathrm{ml})$. The volume of distribution at steady state $\left(V_{\mathrm{ss}}\right)$ was approximately 18-19 litres. The mean terminal half-life is approximately 10-17 hours and stays consistent across doses up to $8 \mathrm{mg} / \mathrm{kg}$ and after single and repeated administration. Total clearance was $0.15-0.3 \mathrm{ml} / \mathrm{min} / \mathrm{kg}$ in healthy subjects and adult patients and is independent of dose after single and repeated administration. Following a single intravenous dose of 14C-micafungin (25 mg) to healthy volunteers, $11.6 \%$ of the radioactivity was recovered in the urine and $71.0 \%$ in the faeces over 28 days. No loading dose is required for micafungin [14]. Recommended standard dosages vary according to the indication and body weight. For treatment of invasive candidosis in adults the daily dose is $100 \mathrm{mg} / \mathrm{d}$ (children $2 \mathrm{mg} / \mathrm{kg} / \mathrm{d}$ if body weight is $\leq 40 \mathrm{~kg}$ ), for treatment of oesophageal candidosis the daily dose is $150 \mathrm{mg} / \mathrm{d}$ (children $3 \mathrm{mg} / \mathrm{kg} / \mathrm{d}$ if body weight is $\leq 40 \mathrm{~kg}$ ), and for prophylaxis of Candida infections in stem cell recipients the daily dose is $50 \mathrm{mg} / \mathrm{d}$ (children $1 \mathrm{mg} / \mathrm{kg} / \mathrm{d}$ if body weight is $\leq 40 \mathrm{~kg}$ ) [64-66].

Anidulafungin displays linear pharmacokinetics across a wide range of once daily doses (15-130 mg). A low intersubject variability in systemic exposure was observed. The steady state was achieved on the first day after a loading dose. It undergoes slow spontaneous biotransformation into an inactive open-ring peptide, and is excreted in the bile [12]. No liver metabolism has been observed. Anidulafungin is not a clinically relevant substrate, inducer, or inhibitor of cytochrome P450 isoenzymes. The pharmacokinetics of anidulafungin are characterised by a rapid distribu- 
tion half-life (0.5-1 hour) and a volume of distribution, 30-50 1, which is similar to total body fluid volume. Anidulafungin is extensively bound (>99\%) to human plasma proteins. No specific tissue distribution studies of anidulafungin have been done in humans. Therefore, no information is available about the penetration of anidulafungin into the cerebrospinal fluid (CSF) and/or across the blood-brain barrier. The tissue concentrations can reach ten times that of plasma as indicated by animal studies [67]. The clearance of anidulafungin is about $1 \mathrm{l} / \mathrm{h}$. Anidulafungin has a predominant elimination half-life of 24 hours that characterises the majority of the plasma concentration-time profile, and a terminal half-life of 40-50 hours that characterises the terminal elimination phase of the profile. The steady state $\mathrm{C}_{\max }$ and trough concentrations $\left(\mathrm{C}_{\mathrm{min}}\right)$ after standard dosing (loading $200 \mathrm{mg}$ followed by $100 \mathrm{mg}$ ) on day 1 is about 7 and $3 \mathrm{mg} / 1$, respectively. Approximately $30 \%$ of the administered radioactive dose was eliminated in the faeces over 9 days, of which less than $10 \%$ was intact drug. Less than $1 \%$ of the administered radioactive dose was excreted in the urine, indicating negligible renal clearance. Weight was identified as a source of variability in clearance in the population pharmacokinetic analysis, but so far weight has little clinical relevance on the pharmacokinetics of anidulafungin, yet. A dose finding study has been performed ranging from 50 to $100 \mathrm{mg} / \mathrm{d}$ (received a loading dose of twice the daily maintenance dose given as a single infusion on day 1) for the indication candidaemia which found that higher dosages (75mg and $100 \mathrm{mg} / \mathrm{d}$ ) are more effective [68]. A large double-blind trial in 601 patients with endoscopically and microbiologically documented esophageal candidosis comparing oral fluconazole (200 mg on day 1, followed by $100 \mathrm{mg}$ per day) with intravenous anidulafungin (100 mg on day 1, followed by $50 \mathrm{mg}$ per day) for 7 days beyond resolution of symptoms (range, 14-21 days) found anidulafungin equally effective [69]. The currently licensed standard dosage of anidulafungin is a $200 \mathrm{mg}$ loading dose followed by $100 \mathrm{mg}$ once daily.

\section{Special Populations}

\section{PATIENTS WITH HEPATIC IMPAIRMENT}

Dose adjustment is also not required in patients with mild and moderate hepatic impairment for all three agents. The AUC may be increased up to $75 \%$ for caspofungin and a dose reduction to $35 \mathrm{mg} / \mathrm{d}$ maintenance therapy is recommended. However, caspofungin and micafungin were not studied in adults with severe hepatic impairment as well as in children (all echinocandins) with any degree of hepatic impairment and should not be given in these situations [12-14]. Only anidulafungin has been studied in patients with severe hepatic impairment and may be given in this condition [53]. Anidulafungin is not metabolized by the liver and no enhanced serum levels of liver enzymes have been found with any level of hepatic impairment. Patients who develop abnormal liver function tests during treatment with micafungin should be evaluated for the risk/benefit ratio. The development of foci of altered hepatocytes (FAH) and hepatocellu- lar tumors after a treatment period of three months or longer were observed in rats with micafungin. Because development of hepatocellular tumors in humans cannot be excluded, a warning was added to the package insert. No dose adjustment is needed for caspofungin in patients with mild hepatic disease, but in case of moderate disease, the $70 \mathrm{mg}$ loading dose should be followed by $35 \mathrm{mg}$ once daily [12-14].

\section{PEDiatric PATIENTS}

Micafungin is approved for use in neonates and children. AUC values were dose proportional over the dose range of $0.5-4 \mathrm{mg} / \mathrm{kg}$. Clearance was influenced by age, with mean values of clearance in younger children (2-11 years) being approximately 1.3 -fold greater than those in older children (12-17 years). Older children had mean clearance values similar to those determined in adult patients. Mean clearance in premature infants is approximately 5 -fold greater than in adults $[56 ; 70]$.

Caspofungin is approved for use in children (12 months to 17 years). In children receiving 1 $\mathrm{mg} / \mathrm{kg} /$ day caspofungin (maximum, $50 \mathrm{mg} / \mathrm{day}$ ), the area under the concentration-time curve over $24 \mathrm{~h}$ (AUC0-24) was significantly smaller (46\% after multiple doses) than that observed in adults receiving $50 \mathrm{mg} /$ day. In children and adolescents receiving 50 $\mathrm{mg} / \mathrm{m}_{2} /$ day (maximum, $70 \mathrm{mg} /$ day), the AUC0-24 following multiple doses was similar to that for the exposure in adults receiving $50 \mathrm{mg} /$ day. Accordingly, Caspofungin administration at $50 \mathrm{mg} / \mathrm{m}_{2} /$ day provides a comparable exposure in children (12 months to 17 years) to that of adult patients treated with 50 $\mathrm{mg} /$ day [63].

Anidulafungin is currently not approved for use in children. Pediatric patients with neutropenia $(2-17$ years of age) receiving $0.75 \mathrm{mg} / \mathrm{kg} /$ day or 1.5 $\mathrm{mg} / \mathrm{kg} /$ day had anidulafungin concentration profiles similar to those of adult patients receiving 50 or 100 $\mathrm{mg} /$ day, respectively [71].

\section{GERIATRIC POPULATION, PREGNANT WOMEN AND NURSING MOTHERS}

No dose adjustment is required for geriatric population. All echinocandins have embryo toxic potential and all three of them have been found in the breast milk of rats. Therefore, they should only be used during pregnancy or in nursing women if benefits overweigh the risks [12-14].

\section{DRUG INTERACTIONS}

Echinocandins are poor substrates for the cytochrome P450 enzymes (caspofungin is the most dependent echinocandin on the CYP450 system and anidulafungin shows the least interaction potential). They also do not influence the P-glycoprotein family. Therefore, there are very few known drug-drug interactions with these drugs. Rifampin, nevirapine, efavirenz, carbamazepine, phenytoin, and dexamethasone can induce the clearance of caspofungin. Increasing the dose of caspofungin to $70 \mathrm{mg}$ daily should be considered if 
concomitant use of these drugs is necessary [16]. Transient elevations of liver function tests have been observed in patients receiving caspofungin and cyclosporine (CsA; and/or tacrolimus) in a phase I trial [72]. Although CsA is a potent inhibitor of CYP3A4 and P-glycoprotein, these pathways are not involved in the metabolism of caspofungin. However, in two cohorts of stem cell and organ (liver) transplant patients receiving concomitantly caspofungin with cyclosporine A or tacrolimus, no or mild liver enzyme elevation was observed $[73 ; 74]$. Caspofungin interacts with tacrolimus and reduces its AUC by $20 \%$. Monitoring of drug concentrations of tacrolimus is required in patients who receive both drugs. Interestingly, both CsA and tacrolimus exhibit a clear in vitro positive interaction with caspofungin against Aspergillus fumigatus in vitro. Microscopic morphological analyses indicate that the calcineurin inhibitors delay filamentation, and in combination with caspofungin there is a positive interaction. These findings even suggest a potential role for combination therapy with calcineurin pathway inhibitors [75]. Micafungin has a potential to increase concentrations of sirolimus, itraconazole and nifedipine. Dose reduction of these drugs may be required. Coadministration with tacrolimus, cyclosporine, fluconazole, prednisolone, ritonavir and rifampin do not alter the pharmacokinetic of any of the drugs [14].

No dosage adjustments are necessary for anidulafungin if coadministered with any other drug [12].

\section{Safety and Adverse Drug Reactions}

Echinocandins are contraindicated in patients with known hypersensitivity to the agents or any of its components. As mentioned above, micafungin includes a warning of possible development of liver tumors. In general, the echinocandins are well tolerated and similar in types of adverse effects. They have a favorable safety profile compared to other antifungals. Infusion related reactions may occur after use of all three echinocandins $(<5 \%)$, but they respond well to antihistamines and the drug needs not to be withdrawn. Thrombophlebitis may occur as well $(<3 \%$; primarily seen in HIV infected patients with peripheral lines) but infusion-related reactions were less frequently observed as compared to liposomal amphotericin when used as empiric antifungal therapy in patients with persistent fever and granulocytopenia [76]. Caspofungin has a somewhat higher frequency of liver-related laboratory abnormalities (1-15\%) compared to the other two drugs [1]. Nausea, vomiting, diarrhea and other mild gastrointestinal symptoms are possible, but rare.

\section{Pharmaco-ECONOMIC Evaluations}

Pharmaco-economic analysis revealed that echinocandins (caspofungin, micafungin) may be more cost-effective than liposomal amphotericin B in the treatment of suspected fungal infections, especially for azole-resistant cases and in patients with renal impairment [77; 78]. In fluconazole-susceptible invasive Candida infections (C. albicans), anidulafungin was found to be su- perior than the azole antifungal in a randomized trial [79]. Whether anidulafungin is cost-effective more than fluconazole needs to be further analyzed. In a model with inputs from the literature in a hypothetical 1000-patient cohort with suspected ICU-acquired invasive candidosis (ICU-AC) treated empirically with either micafungin or fluconazole or no treatment accompanied by a watchful waiting strategy, treatment of suspected ICU-AC (for fluconazole-resistant Candida spp.) with the echinocandin at a dose of $100 \mathrm{mg}$ daily was a cost-effective alternative compared with $400 \mathrm{mg}$ daily FLU or observation alone [80].

Most of these reports were supported by the corresponding manufacturer of the antifungal drug and confirmation of these findings in independent studies is awaited.

\section{REFERENCES}

1. Cappelletty D, Eiselstein-McKitrick K. The echinocandins. Pharmacotherapy 2007 March;27(3):369-88.

2. Denning DW. Echinocandin antifungal drugs. Lancet 2003 October 4;362(9390):1142-51.

3. Edmond MB, Wallace SE, McClish DK et al. Nosocomial bloodstream infections in United States hospitals: a threeyear analysis. Clin Infect Dis 1999 August;29(2):239-44.

4. Wisplinghoff H, Seifert H, Wenzel RP, Edmond MB. Current trends in the epidemiology of nosocomial bloodstream infections in patients with hematological malignancies and solid neoplasms in hospitals in the United States. Clin Infect Dis 2003 May 1;36(9):1103-10.

5. Wisplinghoff $\mathrm{H}$, Bischoff T, Tallent SM et al. Nosocomial bloodstream infections in US hospitals: analysis of 24,179 cases from a prospective nationwide surveillance study. Clin Infect Dis 2004 August 1;39(3):309-17.

6. Pfaller MA, Diekema DJ, Jones RN et al. International surveillance of bloodstream infections due to Candida species: frequency of occurrence and in vitro susceptibilities to fluconazole, ravuconazole, and voriconazole of isolates collected from 1997 through 1999 in the SENTRY antimicrobial surveillance program. J Clin Microbiol 2001 September;39(9):3254-9.

7. Pfaller MA, Diekema DJ. Twelve years of fluconazole in clinical practice: global trends in species distribution and fluconazole susceptibility of bloodstream isolates of Candida. Clin Microbiol Infect 2004 March;10 Suppl 1:11-23.

8. Pappas PG, Kauffman CA, Andes D et al. Clinical practice guidelines for the management of candidiasis: 2009 update by the Infectious Diseases Society of America. Clin Infect Dis 2009 March 1;48(5):503-35.

9. Wiederhold NP, Lewis RE. The echinocandin antifungals: an overview of the pharmacology, spectrum and clinical efficacy. Expert Opin Investig Drugs 2003 August;12(8): 1313-33.

10. Odds FC, Brown AJ, Gow NA. Antifungal agents: mechanisms of action. Trends Microbiol 2003 June;11(6):272-9

11. Pound MW, Townsend ML, Drew RH. Echinocandin pharmacodynamics: review and clinical implications. J Antimicrob Chemother 2010 June;65(6):1108-18.

12. European Medicines Agency . Anidulafungin. http://www ema europa eu/ema/index jsp?curl=pages/ medicines/human/medicines/000788/human_med_000751 jsp\&murl $=$ menus $/$ medicines $/$ medicinesjsp\&mid $=W C 0 b$ 01ac058001d125 2009;

13. European Medicines Agency . Caspofungin. http://www ema europa eu/ema/index jsp?curl=pages/ medicines/human/medicines/000379/human_med_000684 jsp\&murl=menus $/$ medicines $/$ medicines $j$ sp\& $\mathrm{mid}=\mathrm{WCOb}$ 01ac058001d125 2009; 
14. European Medicines Agency . Micafungin. http://www ema europa eu/docs/en_GB/document_libra ry/EPAR_-_Product_Information/human/000734/ WC500031075 pdf 2009;

15. Ostrosky-Zeichner L, Pappas PG. Invasive candidiasis in the intensive care unit. Crit Care Med 2006 March;34(3): 857-63.

16. Chen SC, Slavin MA, Sorrell TC. Echinocandin antifungal drugs in fungal infections: a comparison. Drugs 2011 January $1 ; 71(1): 11-41$.

17. Del PM, Cruz MC, Cardenas ME et al. Synergistic antifungal activities of bafilomycin A(1), fluconazole, and the pneumocandin MK-0991/caspofungin acetate (L-743,873) with calcineurin inhibitors FK506 and L-685,818 against Cryptococcus neoformans. Antimicrob Agents Chemother 2000 March;44(3):739-46.

18. Marchetti O, Moreillon P, Glauser MP et al. Potent synergism of the combination of fluconazole and cyclosporine in Candida albicans. Antimicrob Agents Chemother 2000 September;44(9):2373-81.

19. Ostrosky-Zeichner L, Rex JH, Pappas PG et al. Antifungal susceptibility survey of 2,000 bloodstream Candida isolates in the United States. Antimicrob Agents Chemother 2003 October;47(10):3149-54.

20. Pfaller MA, Diekema DJ, Ostrosky-Zeichner L et al. Correlation of MIC with outcome for Candida species tested against caspofungin, anidulafungin, and micafungin: analysis and proposal for interpretive MIC breakpoints. J Clin Microbiol 2008 August;46(8):2620-9.

21. Pfaller MA, Boyken L, Hollis RJ et al. In Vitro Susceptibility of Invasive Isolates of Candida spp. to Anidulafungin, Caspofungin, and Micafungin: Six Years of Global Surveillance. J Clin Microbiol 2008 January;46(1):150-6.

22. Clinical and Laboratory Standards Institute. Reference Method for Broth Dilution Antifungal Susceptibility Testing of Yeasts; Third Informational Supplement. Clinical and Laboratory Standards Institute 28[15], 1-19. 2008.

23. Cheung C, Guo Y, Gialanella P, Feldmesser M. Development of candidemia on caspofungin therapy: a case report. Infection 2006 December;34(6):345-8.

24. Miller CD, Lomaestro BW, Park S, Perlin DS. Progressive esophagitis caused by Candida albicans with reduced susceptibility to caspofungin. Pharmacotherapy 2006 June; 26(6):877-80.

25. Laverdiere M, Lalonde RG, Baril JG et al. Progressive loss of echinocandin activity following prolonged use for treatment of Candida albicans oesophagitis. J Antimicrob Chemother 2006 April;57(4):705-8.

26. Hernandez S, Lopez-Ribot JL, Najvar LK et al. Caspofungin resistance in Candida albicans: correlating clinical outcome with laboratory susceptibility testing of three isogenic isolates serially obtained from a patient with progressive Candida esophagitis. Antimicrob Agents Chemother 2004 April;48(4):1382-3.

27. Moudgal V, Little T, Boikov D, Vazquez JA. Multiechinocandin- and multiazole-resistant Candida parapsilosis isolates serially obtained during therapy for prosthetic valve endocarditis. Antimicrob Agents Chemother 2005 February;49(2):767-9.

28. Hakki M, Staab JF, Marr KA. Emergence of a Candida krusei isolate with reduced susceptibility to caspofungin during therapy. Antimicrob Agents Chemother 2006 July;50(7):2522-4.

29. Kabbara N, Lacroix C, Peffault de LR et al. Breakthrough C. parapsilosis and C. guilliermondii blood stream infections in allogeneic hematopoietic stem cell transplant recipients receiving long-term caspofungin therapy. Haematologica 2008 April;93(4):639-40.

30. Balashov SV, Park S, Perlin DS. Assessing resistance to the echinocandin antifungal drug caspofungin in Candida albicans by profiling mutations in FKS1. Antimicrob Agents Chemother 2006 June;50(6):2058-63.
31. Kahn JN, Garcia-Effron G, Hsu MJ et al. Acquired echinocandin resistance in a Candida krusei isolate due to modification of glucan synthase. Antimicrob Agents Chemother 2007 May;51(5):1876-8.

32. Schuetzer-Muehlbauer M, Willinger B, Krapf G et al. The Candida albicans Cdr2p ATP-binding cassette (ABC) transporter confers resistance to caspofungin. Mol Microbiol 2003 April;48(1):225-35.

33. Louie A, Deziel M, Liu W et al. Pharmacodynamics of caspofungin in a murine model of systemic candidiasis: importance of persistence of caspofungin in tissues to understanding drug activity. Antimicrob Agents Chemother 2005 December;49(12):5058-68.

34. Petraitiene R, Petraitis V, Groll AH et al. Antifungal activity of LY303366, a novel echinocandin B, in experimental disseminated candidiasis in rabbits. Antimicrob Agents Chemother 1999 September;43(9):2148-55.

35. Nguyen KT, Ta P, Hoang BT et al. Anidulafungin is fungicidal and exerts a variety of postantifungal effects against Candida albicans, C. glabrata, C. parapsilosis, and C. krusei isolates. Antimicrob Agents Chemother 2009 August;53(8):3347-52.

36. Cota J, Carden M, Graybill JR et al. In vitro pharmacodynamics of anidulafungin and caspofungin against Candida glabrata isolates, including strains with decreased caspofungin susceptibility. Antimicrob Agents Chemother 2006 November;50(11):3926-8.

37. Gumbo T, Drusano GL, Liu W et al. Once-weekly micafungin therapy is as effective as daily therapy for disseminated candidiasis in mice with persistent neutropenia. Antimicrob Agents Chemother 2007 March;51(3):968-74.

38. Gumbo T, Drusano GL, Liu W et al. Anidulafungin pharmacokinetics and microbial response in neutropenic mice with disseminated candidiasis. Antimicrob Agents Chemother 2006 November;50(11):3695-700.

39. Gumbo T. Impact of pharmacodynamics and pharmacokinetics on echinocandin dosing strategies. Curr Opin Infect Dis 2007 December;20(6):587-91.

40. Mehta PA, Vinks AA, Filipovich A et al. Alternate-day micafungin antifungal prophylaxis in pediatric patients undergoing hematopoietic stem cell transplantation: a pharmacokinetic study. Biol Blood Marrow Transplant 2010 October;16(10):1458-62.

41. Clemons KV, Espiritu M, Parmar R, Stevens DA. Assessment of the paradoxical effect of caspofungin in therapy of candidiasis. Antimicrob Agents Chemother 2006 April; 50(4):1293-7.

42. Bizerra FC, Melo AS, Katchburian E et al. Changes in cell wall synthesis and ultrastructure during paradoxical growth effect of caspofungin on four different Candida species. Antimicrob Agents Chemother 2011 January;55(1):302-10.

43. Melo AS, Colombo AL, Arthington-Skaggs BA. Paradoxical growth effect of caspofungin observed on biofilms and planktonic cells of five different Candida species. Antimicrob Agents Chemother 2007 September;51(9):3081-8.

44. Fleischhacker M, Radecke C, Schulz B, Ruhnke M. Paradoxical growth effects of the echinocandins caspofungin and micafungin, but not of anidulafungin, on clinical isolates of Candida albicans and C. dubliniensis. Eur J Clin Microbiol Infect Dis 2008 February; 27(2):127-31.

45. Cateau E, Rodier MH, Imbert C. In vitro efficacies of caspofungin or micafungin catheter lock solutions on Candida albicans biofilm growth. J Antimicrob Chemother 2008 July;62(1):153-5.

46. Cocuaud C, Rodier MH, Daniault G, Imbert C. Anti-metabolic activity of caspofungin against Candida albicans and Candida parapsilosis biofilms. J Antimicrob Chemother 2005 September;56(3):507-12.

47. Kuhn DM, Ghannoum MA. Candida biofilms: antifungal resistance and emerging therapeutic options. Curr Opin Investig Drugs 2004 February;5(2):186-97.

48. Lattif AA, Mukherjee K, Chandra J et al. Characterization of biofilms formed by Candida parapsilosis, C. metapsilo- 
sis, and C. orthopsilosis. Int J Med Microbiol 2009 November 19.

49. Weber K, Sohr R, Schulz B et al. Secretion of E,E-farnesol and biofilm formation in eight different Candida species. Antimicrob Agents Chemother 2008 May;52(5):1859-61.

50. Onishi J, Meinz M, Thompson J et al. Discovery of novel antifungal (1,3)-beta-D-glucan synthase inhibitors. Antimicrob Agents Chemother 2000 February;44(2):368-77.

51. Gauthier GM, Nork TM, Prince R, Andes D. Subtherapeutic ocular penetration of caspofungin and associated treatment failure in Candida albicans endophthalmitis. Clin Infect Dis 2005 August 1;41(3):e27-e28.

52. Hope WW, Mickiene D, Petraitis V et al. The Pharmacokinetics and Pharmacodynamics of Micafungin in Experimental Hematogenous Candida Meningoencephalitis: Implications for Echinocandin Therapy in Neonates. J Infect Dis 2008 January 1;197(1):163-71.

53. Dowell JA, Stogniew M, Krause D, Damle B. Anidulafungin does not require dosage adjustment in subjects with varying degrees of hepatic or renal impairment. J Clin Pharmacol 2007 April;47(4):461-70.

54. Morris MI, Villmann M. Echinocandins in the management of invasive fungal infections, part 1. Am J Health Syst Pharm 2006 September 15;63(18):1693-703.

55. Estes KE, Penzak SR, Calis KA, Walsh TJ. Pharmacology and antifungal properties of anidulafungin, a new echinocandin. Pharmacotherapy 2009 January;29(1):17-30.

56. Hope WW, Smith PB, Arrieta A et al. Population pharmacokinetics of micafungin in neonates and young infants. Antimicrob Agents Chemother 2010 June;54(6):2633-7.

57. Gumbo T, Hiemenz J, Ma L et al. Population pharmacokinetics of micafungin in adult patients. Diagn Microbiol Infect Dis 2007 November 15.

58. Nguyen TH, Hoppe-Tichy T, Geiss HK et al. Factors influencing caspofungin plasma concentrations in patients of a surgical intensive care unit. J Antimicrob Chemother 2007 July;60(1):100-6.

59. Andes D, Pascual A, Marchetti O. Antifungal therapeutic drug monitoring: established and emerging indications. Antimicrob Agents Chemother 2009 January;53(1):24-34.

60. Betts RF, Nucci M, Talwar D et al. A Multicenter, doubleblind trial of a high-dose caspofungin treatment regimen versus a standard caspofungin treatment regimen for adult patients with invasive candidiasis. Clin Infect Dis 2009 June 15;48(12):1676-84

61. Cornely OA, Lasso M, Betts R et al. Caspofungin for the treatment of less common forms of invasive candidiasis. J Antimicrob Chemother 2007 Aug;60(2):363-9. Epub 2007 May 26.

62. Stone JA, Holland SD, Wickersham PJ et al. Single- and multiple-dose pharmacokinetics of caspofungin in healthy men. Antimicrob Agents Chemother 2002 March;46(3): 739-45.

63. Walsh TJ, Adamson PC, Seibel NL et al. Pharmacokinetics, safety, and tolerability of caspofungin in children and adolescents. Antimicrob Agents Chemother 2005 November;49(11):4536-45.

64. van Burik JA, Ratanatharathorn V, Stepan DE et al. Micafungin versus fluconazole for prophylaxis against invasive fungal infections during neutropenia in patients undergoing hematopoietic stem cell transplantation. Clin Infect Dis 2004 November 15;39(10):1407-16.

65. Kuse ER, Chetchotisakd P, da Cunha CA et al. Micafungin versus liposomal amphotericin B for candidaemia and invasive candidosis: a phase III randomised double-blind trial. Lancet 2007 May 5;369(9572):1519-27.

66. de Wet N, Llanos-Cuentas A, Suleiman J et al. A randomized, double-blind, parallel-group, dose-response study of micafungin compared with fluconazole for the treatment of esophageal candidiasis in HIV-positive patients. Clin Infect Dis 2004 September 15;39(6):842-9.
67. Damle B, Stogniew M, Dowell J. Pharmacokinetics and tissue distribution of anidulafungin in rats. Antimicrob Agents Chemother 2008 July;52(7):2673-6.

68. Krause DS, Reinhardt J, Vazquez JA et al. Phase 2, randomized, dose-ranging study evaluating the safety and efficacy of anidulafungin in invasive candidiasis and candidemia. Antimicrob Agents Chemother 2004 June;48(6): 2021-4.

69. Krause DS, Simjee AE, van Rensburg C et al. A randomized, double-blind trial of anidulafungin versus fluconazole for the treatment of esophageal candidiasis. Clin Infect Dis 2004 September 15;39(6):770-5.

70. Hope WW, Seibel NL, Schwartz CL et al. Population pharmacokinetics of micafungin in pediatric patients and implications for antifungal dosing. Antimicrob Agents Chemother 2007 October;51(10):3714-9.

71. Benjamin DK, Jr., Driscoll T, Seibel NL et al. Safety and pharmacokinetics of intravenous anidulafungin in children with neutropenia at high risk for invasive fungal infections. Antimicrob Agents Chemother 2006 February;50(2):632-8.

72. Kartsonis NA, Nielsen J, Douglas CM. Caspofungin: the first in a new class of antifungal agents. Drug Resist Updat 2003 August;6(4):197-218.

73. Saner F, Gensicke J, Rath P et al. Safety profile of concomitant use of caspofungin and cyclosporine or tacrolimus in liver transplant patients. Infection 2006 December;34(6):328-32.

74. Marr KA, Hachem R, Papanicolaou G et al. Retrospective study of the hepatic safety profile of patients concomitantly treated with caspofungin and cyclosporin A. Transpl Infect Dis 2004 September;6(3):110-6.

75. Steinbach WJ, Schell WA, Blankenship JR et al. In vitro interactions between antifungals and immunosuppressants against Aspergillus fumigatus. Antimicrob Agents Chemother 2004 May;48(5):1664-9.

76. Walsh TJ, Teppler H, Donowitz GR et al. Caspofungin versus liposomal amphotericin B for empirical antifungal therapy in patients with persistent fever and neutropenia. N Engl J Med 2004 September 30;351(14):1391-402.

77. Bruynesteyn K, Gant V, McKenzie C et al. A cost-effectiveness analysis of caspofungin vs. liposomal amphotericin B for treatment of suspected fungal infections in the UK. Eur J Haematol 2007 June; 78(6):532-9.

78. Cornely OA, Sidhu M, Odeyemi I et al. Economic analysis of micafungin versus liposomal amphotericin B for treatment of candidaemia and invasive candidiasis in Germany. Curr Med Res Opin 2008 June;24(6):1743-53.

79. Reboli AC, Rotstein C, Pappas PG et al. Anidulafungin versus fluconazole for invasive candidiasis. $\mathrm{N}$ Engl J Med 2007 June 14;356(24):2472-82.

80. Zilberberg MD, Kothari S, Shorr AF. Cost-effectiveness of micafungin as an alternative to fluconazole empiric treatment of suspected ICU-acquired candidemia among patients with sepsis: a model simulation. Crit Care 2009; 13(3):R94.

Received: February 11, 2011 / Accepted: February 15, 2011

Address for correspondence:

Prof. Dr. med. Markus Ruhnke

Medizinische Klinik und Poliklinik,

m. S. Onkologie und Hämatologie

Charité Universitätsmedizin Berlin, Campus Charité Mitte

Charitéplatz 1,

10117 Berlin

Germany

Phone: +49-(0)30-450-513102

Fax: +49- (0)30-450-513907,

Email: markus.ruhnke@charite.de 